\title{
The novel mutations of GATA4 gene in Chinese patients with sporadic congenital heart defects
}

\author{
Jing-Dong Ding*, Jiayi Tong, Kairu Li, Xiang Fang, Hao Li, Xiaoli Zhang, YuyuYao and Genshan Ma \\ Department of Cardiology, Zhongda hospital \& School of Clinical Medicine, Southeast University, Nanjing, P.R. China
}

\begin{abstract}
Background: Congenital heart defects (CHD) are a major cause of substantial morbidity and mortality in infants. Recent reports have identified that mutations in a few genes, including T-BOX5, NKX2.5, EVC and GATA4, are associated with CHD. The prevalence of GATA4 gene mutations in Chinese patients with sporadic $\mathrm{CHD}$ is unknown. Here, the authors aimed to examine Chinese patients with sporadic CHD to find out whether there is any mutation in GATA4 accounting for the etiology.
\end{abstract}

Methods: A cohort of 99 unrelated patients with sporadic CHD was included in the study, among which 93 patients had simple heart defects, such as atrial septal defect (ASD), ventricular septal defect (VSD), pulmonary valvar stenosis (PVS) and patent ductus arteriosus (PDA) and 6 patients had a variety of complex heart defects. A total of 90 unrelated ethnically matched healthy individuals were recruited as controls. After amplifying the exon 3 of the GATA4 gene by polymerase chain reaction (PCR), we purified the PCR products and conducted the sequencing reaction, analyzed the mutation of the GATA4 gene.

Results: Three inserted mutations $(52,58,61)$ with base A in the exon 3 of the GATA4 gene were identified in 3 of 21 patients with PDA, but none were found in controls.

Conclusion: Our results suggest that GATA4 gene mutations may be one of etiologic causes of congenital heart defect in Chinese people. However, the mechanism by which this mutation contributes to the development of a congenital heart defect remains to be ascertained.

\section{Introduction}

Congenital heart defects (CHD) is the most prevalent form of developmental abnormality in newborns, with an estimated prevalence of $1 \%$, and is the leading non-infectious cause of infant mortality, with more than $29 \%$ of neonates who die of a birth defect having a cardiovascular deformity [1]. Nevertheless, the aetiology of CHD in the majority of cases remains largely unclear. CHD is a diverse group of diseases determined by genetic and environmental factors. Therefore, screening for disease causing or susceptibility genes, identifying new genetic mutations associated with $\mathrm{CHD}$ and further studying the functions of CHD susceptibility genes are focused on current genetic research. Heart formation is a complex process regulated by many transcription factors. Although most of $\mathrm{CHD}$ cases are sporadic, there are several genes which were found to be associated with CHD, including NKX2.5, TBX5, GATA4, etc. Recent studies have identified mutations in these genes which could cause heart developmental anomalies and lead to heart disease. Mutations of NKX2.5 have been reported that might cause congenital heart diseases [2-4]. Recently, heterozygous mutations in the GATA4 zinc finger transcription factor gene have been identified in patients with $\mathrm{CHD}$, such as ventricular septal defect (VSD) [5,6], atrial septal defect (ASD) [7-9], tetralogy of Fallot (TOF) [10], and so on.

The GATA4 gene is one of the genes encoding zinc-finger transcriptional factors which are vital to the cardiac development. The GATA4 protein binds the GATA motif consensus sequence to modulate the transcription of target genes. GATA4 has 442 amino acids with two transactivation domains; two zinc fingers, one at the N-terminus (NZf) and the other at the C-terminus (CZf); and a nuclear localization signal (NLS), for import into the nucleus. The CZf and the adjacent basic domain of GATA4 have dual functions in both DNA binding and nuclear localization. The amino acids 270-324 fragment within the DNA-binding domain at amino acids 216-324 has been identified as the minimal, functional NLS region for actively transporting GATA4 into the nucleus of both HeLa cells and cardiac myocytes [11].

To identify the mutations of GATA4 gene in Chinese patients with sporadic $\mathrm{CHD}$, we analyzed the sequence of the transcription factor GATA4 using DNA extracted from whole peripheral blood of 99 consecutive patients diagnosed with CHD.

\section{Methods}

\section{Study subjects}

99 unrelated CHD patients (38 men, 61 women; mean age $21.5 \pm$ 11.8, range 1 to 65 years) obtained from Department of Cardiology, Zhongda hospital and School of Clinical Medicine Southeast University, Nanjing, China and 90 healthy volunteers matched for age and gender ( 42 men, 48 women; mean age $22.1 \pm 12.3$, range 12 to

Correspondence to: Jing-dong Ding, Department of Cardiology, Zhongda hospital and School of Clinical Medicine, Southeast University, 87 Ding Jia Qiao Road, Nanjing, 210009, China, Tel: 86-25-83272042; Fax: 86-25-83272042; E-mail: dingjiandong@163.com

Key words: GATA4, congenital heart defect, gene mutation

Received: May 28, 2015; Accepted: June 26, 2015; Published: June 29, 2015 
Table 1. CHD patients for the detection of NKX2.5 and GATA4 gene mutations.

\begin{tabular}{|l|c|}
\hline Phenotype & Number of patients \\
\hline Complex forms of CHD & 6 \\
\hline Atrial septal defect (ASD) & 35 \\
Ostium secundum & 30 \\
\hline Sinus venosus & 5 \\
\hline Ventricular septal defect (VSD) & 24 \\
Perimembranous & 19 \\
Membranous & 3 \\
Muscular & 1 \\
Infrapulmonary & 1 \\
\hline Patent ductus arteriosus & 21 \\
\hline Pulmonary valvar stenosis & 13 \\
\hline Total & 99 \\
\hline
\end{tabular}

64 years) who served as control subjects were included in the study (Table1). All participants of this study were of Chinese Han nationality.

The clinical features of these patients include 6 with complex forms of CHD, 35 with atrial septal defect (ASD), 24 with ventricular septal defect (VSD), 13 with pulmonary valvar stenosis (PVS), 21 with patent ductus arteriosus (PDA). All patients were sporadic.

Participants were evaluated by medical history, physical examinations, chest X-ray film, twelve-lead electrocardiogram (ECG) and two-dimensional transthoracic echocardiography with colour flow Doppler. Transesophageal echocardiography, cardiac catheterization, electrophysiology study, and/or cardiac surgery had been performed in some individuals.

This study protocol was approved by the institutional ethics committee for human subjects. Informed consent was obtained from all adult participants and from parents or guardians of minors prior to participation in the study.

All of them were informed about procedures related to the study.

\section{Genomic DNA extraction}

Peripheral blood samples were taken from individuals. Genomic DNA was isolated from the whole blood leukocytes of participants with the DNA extraction Kit (Shanghai Qikang Biological Science and Technology Co.,Ltd.), according to the manufacturer's protocol.

\section{Polymerase chain reaction (PCR)}

The primer of the exon3 of GATA4 designed according to the genomic sequence and cDNA sequence of GATA4 was synthesized by Shanghai Biological Engineering Technology \& Services Co., Ltd. (Shanghai, China). The PCR products including all coding sequences and the boundary sequences of exon were $404 \mathrm{bp}$. All reactions started with 2 minutes at $95^{\circ} \mathrm{C}$ followed by 35 cycles of 45 seconds at $95^{\circ} \mathrm{C}, 30$ seconds at $60^{\circ} \mathrm{C}$ or $61^{\circ} \mathrm{C}$, and 45 seconds at $72^{\circ} \mathrm{C}$ and finished with a 10 -minute extension period at $72^{\circ} \mathrm{C}$. DMSO $(0.2 \mathrm{~mL} / 20$-uL reaction $)$ was added to standard reagents for reaction $2 \mathrm{~A}$. Enhancer solution (PCR enhancer system, Gibco BRL) was added to standard reagents at $1 \mathrm{X}$ concentration for reaction $2 \mathrm{~B}$.

\section{DNA sequence analysis}

All the PCR products were purified by DNA gel extraction kit (Shanghai Biocolor BioScience \& Technology Company (BBST)) and sequenced on ABI PRISM3700 automatic DNA sequence analyzer. Sequence alterations were examined in context of the open reading frame to determine whether the alteration would change the corresponding amino acid. All experiments were performed in duplicate, and at least three separate transfections were carried out.

\section{Statistics}

Statistical comparison of the CHD groups with control group was carried out using one-way analysis of variance and Dunnett's $t$ test. The accepted level of significance was $p<0.05$.

\section{Results}

Three insertion mutations $(52,58,61)$ with base A in the exon 3 of the GATA4 gene were identified in 3 of 21 patients with PDA (Figure 1). The mutations were not detected in the controls subjects.

The sequence results were shown in Figure 2, we identified three insertion mutations $(52,58,61)$ with base A in the exon 3 of the GATA4 gene were identified in 3 of 21 patients with PDA and the previously reported mutations were not found.

\section{Discussion}

The heart is the first functional organ in the developing embryos, and the appropriate delivery of oxygen and nutrients through the circulatory system is prerequisite for embryonic growth and survival. The formation of the heart involves a precisely coordinated process of cellular differentiation and integrated multicellular morphogenesis, and even a minute perturbation of this process gives rise to congenital heart defects. The susceptibility of the heart to malformation is reflected by the high incidence of CHD (nearly $1 \%$ of live births) [12].

GATA transcription factors are a family of transcription factors

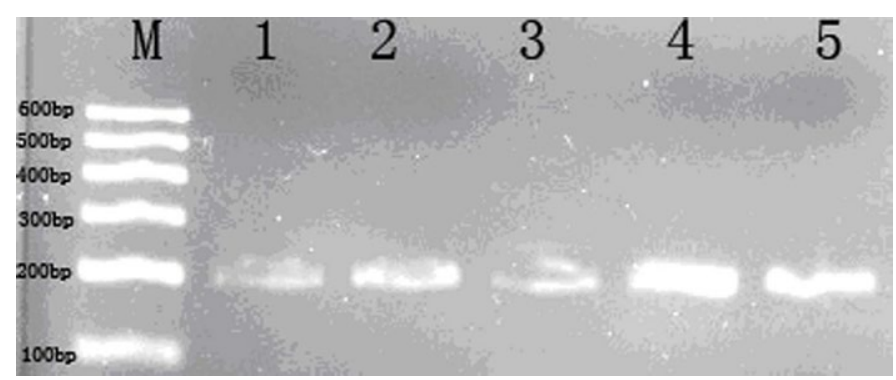

M: DNA marker; 1,2,3: patients with PDA; 4,5: control subjects

Figure 1. Electrophoretic analysis of PCR products of GATA4 gene in exon 3.

a:
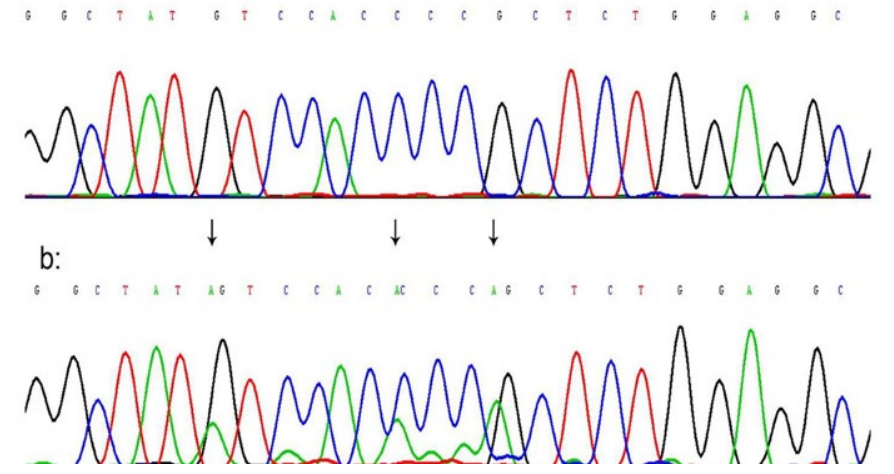

A: Normal sequence in the exon 3 of GATA4

B: Three inserted mutations $(52,58,61)$ with base A in the exon 3 of the GATA4

Figure 2. Sequence analyses of the genomic DNA of GATA4 in the patients with CHD. 
characterized by the ability to bind to the consensus DNA sequence 'GATA'. To date, 6 members of the GATA family have been identified in vertebrates, of which GATA4, GATA5 and GATA6 are expressed mainly in the developing heart and in several endodermal lineages. GATA4 is an important transcription factor for cardiac morphogenesis and development [13]. GATA4 is located on chromosome 8p23.1-p22, consists of seven exons and codes for a 442- amino-acid protein. GATA4 has two zinc-finger DNA binding motifs, and the DNAprotein interactions are adjusted as protein-protein interactions.

In this study, we identified three inserted mutations $(52,58,61)$ with base A in the exon 3 of the GATA4 gene in 3 of 21 patients with PDA. Pehlivan first proposed that the haploin sufficiency of GATA4 may be involved in the etiology of the congenital heart disease observed in some patients with del (8) (p23.1) [14]. Deletion of the GATA4 gene has been found in patients with congenital cardiovascular diseases. The phenotypes of these congenital cardiovascular diseases, such as ASD, VSD, double-outlet right ventricle (DORV), complete total atrioventricular canal, pulmonary stenosis (PS), and hypoplastic left heart syndrome (HLHS) vary [15]. Garg and associates reported that the G296S mutation disrupts the DNA-binding and transactivation activity of GATA4 and destroys the synergy in transcriptional activation between GATA4 and its cofactor TBX5, resulting in heart anomalies such as pulmonary stenosis, atrioventricular septal defect, aortic regurgitation, and patent ductus arteriosus, in addition to ASD [16]. Further analysis of the GATA4 gene in congenital cardiovascular disease showed that the mutation of GATA4 causes ASD, VSD, PS, TOF, and AVSD/ECD [5-10,17,18].

It has been demonstrated that GATA4, which is expressed throughout the developing heart, is essential for heart formation, through interaction with other transcription factors including NKX2.5 [19]. The GATA4 (Gly296Ser) mutation affects a highly conserved amino acid localised between the $\mathrm{C}$ terminal zinc finger and the nuclear localising signal. This, in turn, not only changes the DNA binding affinity and the transactivation of downstream targets, but also disrupts the interaction between GATA4 and TBX5 [16]. This suggests that GATA4, TBX5, and NKX2.5 may form a complex required for suitable septation of the heart.

In conclusion, we report three inserted mutations $(52,58,61)$ with base A in the exon 3 of the GATA4 gene, which is reported for the first time. Our findings help in developing the research of the mutation spectrum of GATA4 associated with CHD in human and expand the knowledge about the phenotype spectrum and the prevalence of GATA4 mutations among Chinese patients with sporadic CHD patients.

In summary, the identification of a new GATA4 mutation not only further supports the important role of GATA4 in congenital heart disease but also provides useful information for genetic diagnosis and counseling of CHD.

\section{Acknowledgement}

We thank Qin Chai and Xuedong Li for collecting the blood samples. We also thank the patients and the healthy controls for their invaluable contributions in this study. This study was supported by grant 200601055 from the Science and Technology Planning Project of Nanjing City, China.

\section{Funding}

Supported by grant 200601055 from the Science and Technology Planning Project of Nanjing City, China.

\section{References}

1. Lloyd-Jones D, Adams R, Carnethon M, De Simone G, Ferguson TB, et al. (2009) American Heart Association Statistics Committee and Stroke Statistics Subcommittee: Heart disease and stroke statistics--2009 update: a report from the American Heart Association Statistics Committee and Stroke Statistics Subcommittee. Circulation 119: e21-181. [Crossref]

2. Beffagna G, Cecchetto A, Dal Bianco L, Lorenzon A, Angelini A, et al. (2013) R25C mutation in the NKX2.5 gene in Italian patients affected with non-syndromic and syndromic congenital heart disease. J Cardiovasc Med (Hagerstown) 14: 582-586. [Crossref]

3. Ding JD, Li KR, Zhang XL, Yao YY, Reng LQ, et al. (2009) Preliminary exploration of transcription factor Nkx2.5 mutations and congenital heart diseases. Zhonghua Yi Xue Za Zhi 89: 1114-1116. [Crossref]

4. Wang J, Liu XY, Yang YQ (2011) Novel NKX2-5 mutations responsible for congenital heart disease. Genet Mol Res 10: 2905-2915. [Crossref]

5. Xiong F, Li Q, Zhang C, Chen Y, Li P, (2013) Analyses of GATA4, NKX2.5, and TFAP2B genes in subjects from southern China with sporadic congenital heart disease. Cardiovasc Pathol 22: 141-145. [Crossref]

6. Yang YQ, Tang YQ, Liu XY, Lin XP, Chen YH(2010)Anovel GATA4 mutation leading to congenital ventricular septal defect. Zhonghua Yi Xue Yi Chuan Xue Za Zhi 27: 512-516. [Crossref]

7. Liu XY, Wang J, Zheng JH, Bai K, Liu ZM, et al. (2011) Involvement of a novel GATA4 mutation in atrial septal defects. Int J Mol Med 28: 17-23. [Crossref]

8. Hamanoue H, Rahayuningsih SE, Hirahara Y, Itoh J, Yokoyama U, et al. (2009) Genetic screening of 104 patients with congenitally malformed hearts revealed a fresh mutation of GATA4 in those with atrial septal defects. Cardiol Young 19: 482-485.

9. D'Amato E, Giacopelli F, Giannattasio A, D'Annunzio G, Bocciardi R, et al. (2010). Genetic investigation in an Italian child with an unusual association of atrial septal defect, attributable to a new familial GATA4 gene mutation, and neonatal diabetes due to pancreatic agenesis. Diabet Med 27: 1195-1200. [Crossref]

10. Nemer G, Fadlalah F, Usta J, Nemer M, Dbaibo G, et al. (2006) A novel mutation in the GATA4 gene in patients with Tetralogy of Fallot. Hum Mutat 27: 293-294. [Crossref]

11. Philips AS, Kwok JC, Chong BH (2007) Analysis of the signals and mechanisms mediating nuclear trafficking of GATA-4. Loss of DNA binding is associated with localization in intranuclear speckles. J Biol Chem 282: 24915-24927. [Crossref]

12. Akazawa H, Komuro I (2005) Cardiac transcription factor Csx/Nkx2-5: Its role in cardiac development and diseases. Pharmacology \& Therapeutics 107: 252-68. [Crossref]

13. Tomita-Mitchell A, Maslen CL, Morris CD, Garg V, Goldmuntz E (2007) GATA4 sequence variants in patients with congenital heart disease. J Med Genet 44: 779-783. [Crossref]

14. Pehlivan T, Pober BR, Brueckner M, Garrett S, Slaugh R (1999) GATA4 haploinsufficiency in patients with interstitial deletion of chromosome region $8 \mathrm{p} 23.1$ and congenital heart disease. Am J Med Genet 83: 201-206. [Crossref]

15. Matsuoka R (2007) GATA4 mutation and congenital cardiovascular diseases: importance of phenotype and genetic background clarification. J Mol Cell Cardiol 43: 667-669. [Crossref]

16. Garg V, Kathiriya IS, Barnes R, Schluterman MK, King IN, (2003) GATA4 mutations cause human congenital heart defects and reveal an interaction with TBX5. Nature 424 443-447. [Crossref]

17. Sarkozy A, Conti E, Neri C, D'Agostino R, Digilio MC, (2005) Spectrum of atrial septal defects associated with mutations of NKX2.5 and GATA4 transcription factors. J Med Genet 42: e16. [Crossref]

18. Schluterman MK, Krysiak AE, Kathiriya IS, Abate N, Chandalia M, (2007) Screening and biochemical analysis of GATA4 sequence variations identified in patients with congenital heart disease. Am J Med Genet A 143A: 817-823. [Crossref]

19. Durocher D, Charron F, Warren R, Schwartz RJ, Nemer M (1997) The cardiac transcription factors Nkx2-5 and GATA-4 are mutual cofactors. EMBO $J$ 16: 56875696. [Crossref]

Copyright: (C2015 Ding JD. This is an open-access article distributed under the terms of the Creative Commons Attribution License, which permits unrestricted use, distribution, and reproduction in any medium, provided the original author and source are credited. 